Available online at GSC Online Press Directory

GSC Biological and Pharmaceutical Sciences

e-ISSN: 2581-3250, CODEN (USA): GBPSC2

Journal homepage: https://www.gsconlinepress.com/journals/gscbps

(RESEARCH ARTICLE)

\title{
Formulation and Evaluation of the sea cucumber, Holothuria arenicola extract incorporated skin cream
}

\author{
Ayman Saber Mohamed ${ }^{1,}{ }^{*}$, Sohair Ramadan Fahmy ${ }^{1}$ and Abdelaziz A. Elsayed ${ }^{2}$ \\ ${ }^{1}$ Zoology Department - Faculty of Science - Cairo University, Egypt \\ ${ }^{2}$ Department of Zoology, Faculty of Science, Zagazig University, Egypt.
}

Publication history: Received on 15 November 2020; revised on 24 November 2020; accepted on 27 November 2020

Article DOI: https://doi.org/10.30574/gscbps.2020.13.2.0379

\begin{abstract}
Background: Cucumber extract is often used for skin problems, wrinkles, sunburn, and as an antioxidant. Thereby, the main objective of the present investigation was to develop a topical skincare cream (w/o) loaded with the sea cucumber, Holothuria arenicola extract (HaE).

Methods: Oil in water emulsion-based cream was prepared by incorporating liquid paraffin, soft wax, cetostearyl alcohol in the oil phase, and borax in the water phase respectively with $1 \mathrm{gm}$ of $\mathrm{HaE}$. The evaluation of $\mathrm{HaE}$ cream was done on different parameters like ph, viscosity, spreadability, extrudability, irritancy and stability.

Results: HaE showed good appearance, homogeneity, spreadability, diffusion, consistency, pH, extrudability, and spreadability without any irritancy to skin. The present results showed that $\mathrm{HaE}$ cream has radical scavenging activity in range from 57 to $70 \%$ and NO scavenging activity in range from 25 to $49 \%$. Conclusion: The formulated HaE cream was successfully developed that met the relevant pharmaceutical characteristics form. The developed HaE cream could be added in topical formulations in order to protect skin against damage caused by free radicals due to its antioxidant activity.
\end{abstract}

Keywords: Holothuria arenicola; Antioxidant; Cream; skin

\section{Introduction}

Cosmeceuticals are cosmetic-pharmaceutical hybrids, containing active ingredients in creams, lotions, and ointments [1]. Semisolids constitute a significant proportion of pharmaceutical dosage forms intended to produce desired therapeutic action. Creams are semisolid dosage forms that contain one or more drug substances deliberated for application to the skin or mucous membrane. Emulsions are a class of dispersed systems consisting of two immiscible liquids. Oil in Water $(\mathrm{O} / \mathrm{W})$ emulsions are the most commonly used cosmetic delivery systems that supply moisture to the skin and improve the skin condition by forming the occlusive barrier on the skin.

In recent years, extensive studies have been conducted to explore biological activities, nutritional value, and potential health benefits of marine-based bioactive substances. [2,3]Natural formulations of cosmetics have a growing demand in the world market and are an invaluable gift of nature. These formulations always have attracted considerable attention because of their good activity and comparatively lesser or nil side effects with synthetic drugs. Thus, the cosmetic industry is seeking alternative products of natural origin and avoiding the use of synthetic ingredients [4]. Marine resources represent an underexploited source of highly diverse valuable compounds [5] with potential

\footnotetext{
${ }^{*}$ Corresponding author: Dr. Ayman Saber Mohamed

Ph.D. - Zoology Department - Faculty of Science - Cairo University.
}

Copyright (C) 2020 Author(s) retain the copyright of this article. This article is published under the terms of the Creative Commons Attribution Liscense 4.0 
applications for the formulation of nutraceuticals and cosmetics [6]. Sea cucumbers are marine animals from the class Holothuroidea and have been conventionally employed as medicines owing to their therapeutic efficacy in various diseases. Several studies have already reported multi-faceted biological activities of the sea cucumbers species, the antioxidant, wound healing, and anti-ulcerogenic potential among the most commonly reported. More recently, it was rationalized that a formulation containing sea cucumbers extracts would be highly beneficial in cosmetic industries [7]. Cucumber extract is often used for skin problems, wrinkles, sunburn and as an antioxidant. The most important and abundant sea cucumber species in the Mediterranean Sea on the Egyptian coast is Holothuria arenicola.

Oxidative stress plays an important role in skin aging [8,9]. Antioxidant molecules slow the process of aging either by preventing free radicals from oxidizing sensitive biological molecules or by reducing the formation of free radicals and quenching the already formed reactive oxygen species [ROS) [10]. Consequently, cosmetology has a significant role in the prevention and attenuation of skin aging through the formulation of new substances with effective antioxidant activity, to be incorporated on cosmetic products for daily care [11]. Topical supplementation with antioxidants is regarded as a useful strategy that may improve skin antioxidant capacity to reduce ROS induced skin damages [12]. The antioxidant activity of the sea cucumber, Holothuria arenicola has been evident and up to date, there is no cosmetics formulation for such sea cucumber in Egypt. Thereby, the main objective of the present investigation was to develop a topical skincare cream [w/o] loaded with the sea cucumber, Holothuria arenicola extract [HaE].

\section{Material and methods}

\subsection{Sample collection and preparation}

Sea cucumbers (Holothuria arenicola) were collected from Abu-Qir Bay in the Egyptian Mediterranean coast at the eastern Alexandrian coast (May-June 2020). The animals were transported to our laboratory in an icebox containing ice cubes and a few pinches of table salt. The animals were immediately washed under running tap water and cut open, and all visceral organs were removed and then the body walls of the animals were stored at $-20^{\circ} \mathrm{C}$ until processing. The phosphate buffer extract was prepared according to the method of Yasumoto et al. [13]. The body wall of the animals animals was cut into small parts and blended in phosphate buffer (in a volume $=4 \mathrm{ml} \times$ tissue weight) and extracted at room temperature $\left(25^{\circ} \mathrm{C}\right)$ with $\mathrm{pH} 7.2$ for 5 hours, the filtered was collected. The collected, filtered off the Sea cucumbers concentrated and lyophilized using a lyophilizer (LABCONCO, shell freeze system, USA).

\subsection{Formulation of animal Ointments}

Oil in water emulsion-based cream was prepared by incorporating liquid paraffin, soft wax, cetostearyl alcohol in the oil phase and borax in the water phase respectively. Both the oil and aqueous phases were heated to $75^{\circ} \mathrm{C}$. After heating, the water phase was added into the oil phase with continuous stirring until homogenous cream was formed. After complete emulsification, $\mathrm{HaE}(1 \mathrm{gm})$ was added when the temperature dropped to $55{ }^{0} \mathrm{C} \pm 60{ }^{\circ} \mathrm{C}$. (Table 1 )

Table 1 Cream constituents

\begin{tabular}{|l|l|}
\hline Constituents & Quantity \\
\hline Liquid Paraffin & $30 \mathrm{gm}$ \\
\hline Soft Wax & $9 \mathrm{gm}$ \\
\hline Cetostearyl Alcohol & $2 \mathrm{gm}$ \\
\hline Borax & $0.6 \mathrm{gm}$ \\
\hline Water & $20 \mathrm{ml}$ \\
\hline
\end{tabular}

\subsection{Physical properties of the cream}

\subsubsection{Color, odor, and consistency}

The color, odor, and consistency of the formulated ointments were examined visually.

\subsubsection{Determination of $\mathrm{pH}$}

$5 \pm 0.01 \mathrm{~g}$ of the Cream was weighed accurately in a $100 \mathrm{ml}$ beaker. $45 \mathrm{ml}$ of water was added \& dispersed the Cream in it. The $\mathrm{pH}$ of the suspension was determined at $27 \mathrm{o} \mathrm{C}$ using the $\mathrm{pH}$ meter. 


\subsubsection{Diffusion study}

The diffusion study was carried out by preparing agar nutrient medium of any concentration. It was poured into petri dish. A hole bored at the center and ointment was placed in it. After $1 \mathrm{hr}$ the distance that the ointments get diffused was measured [14].

\subsubsection{Viscosity}

Brookfield digital viscometer was used to measure the viscosity (in cps) of the prepared ointment formulations as such that is in a semisolid state [15].

\subsubsection{Spreadability}

It is the most desirable property of an ointment that decides the extent of the area to which the cream readily spreads on application to the skin or affected part. The spreadability was expressed in seconds taken by two slides to slip off from ointment placed in between the slides under the direction of a certain load. The lesser the time is taken for the separation of two slides, the better the spreadability [16]. Spread ability was calculated by using the formula.

$\mathrm{S}=(\mathrm{M} \cdot \mathrm{L} / \mathrm{T})$

Where, $\mathrm{S}=$ Spread ability,

$\mathrm{M}=$ Weight tied to upper slide,

$\mathrm{L}=$ Length of glass slides and

$\mathrm{T}=$ Time taken to separate the slides

\subsubsection{Loss on drying (LOD)}

LOD was determined by placing the formulation in petri-dish on a water bath and dried for the temperature $1050 \mathrm{oC}$.

\subsubsection{Phase separation study for Emulsion bases}

The ointments formulated using emulsion bases were evaluated for the signs of phase separation on Centrifugation at low, medium, and high speeds. A specific quantity of ointment was filled into the centrifuge tube and kept in the centrifuge. Then it was subjected to rotations at low speed for 5 mins followed by medium speed for 5 mins and high speed for 5 mins and any signs of separation of phases and change in consistency were checked [17].

\subsubsection{Test for Thermal Stability}

Thermal stability of the formulation was determined by the humidity chamber controlled at $60-70 \% \mathrm{RH}$ and $37 \pm 10 \mathrm{C}$

\subsubsection{Stability studies}

Stability testing of drug products begins as a part of drug discovery and ends with the demise of the compound or commercial product. To assess the drug and formulation stability, stability studies were done according to ICH guidelines. The stability studies were carried out as per ICH guidelines. The cream-filled in a bottle and kept in the humidity chamber maintained at $30 \pm 2^{\circ} \mathrm{C} / 65 \pm 5 \% \mathrm{RH}$ and $40 \pm 2^{\circ} \mathrm{C} / 75 \pm 5 \% \mathrm{RH}$ for two months. At the end of the studies, samples were analyzed for the physical properties and viscosity [18].

\subsubsection{Tube extrudability}

In the present study, the method adopted for evaluating cream formulation for extrude ability was based upon the quantity in percentage cream extruded from a tube on the application of finger pressure. More quantity extruded better was extrude ability. The formulation understudy was filled in a clean, lacquered aluminum collapsible 5 grams tube with a nasal tip of $5 \mathrm{~mm}$ opening and apply the pressure on the tube with the help of a finger. Tube extrude ability was then determined by measuring the amount of cream extruded through the tip when pressure was applied on the tube.

\subsection{Irritancy test}

Mark an area (1sq.cm) on the left-hand dorsal surface. The cream was applied to the specified area and time was noted. Irritancy, erythema, edema, was checked if any for regular intervals up to $24 \mathrm{hrs}$ and reported [19].

\subsection{Free radical scavenging activity}

The free radical scavenging activity of HaE cream was analyzed by the DPPH assay [20]. A $1.0 \mathrm{ml}$ of the cream, at gradient final concentrations of $10-50 \mathrm{mg} / \mathrm{ml}$, was mixed with $2 \mathrm{ml}$ of $0.3 \mathrm{mM}$ DPPH solution in $\mathrm{MeOH}$ in a cuvette. The 
absorbance was taken at $517 \mathrm{~nm}$ after 20 minutes of incubation in the dark at room temperature. The experiment was done in triplicates. The percentage free radical scavenging activity was calculated as follows:

Where, RSA is the Radical Scavenging Activity;

Abs control is the absorbance of DPPH radical + ethanol;

Abs sample is the absorbance of DPPH radical + extract.

\subsection{Nitric oxide scavenging assay}

The nitric oxide scavenging activity of HaE cream was analyzed by the Govindarajan et al. assay [21]. A $1.0 \mathrm{ml}$ of the cream, at gradient final concentrations of $10-50 \mathrm{mg} / \mathrm{ml}$, was mixed with $0.5 \mathrm{ml}$ of sodium nitroprusside (5mM) and incubate for $30 \mathrm{~min}$. Then $1.5 \mathrm{ml}$ of Griess reagent was added to each test tube. The absorbance was measured, immediately, at $546 \mathrm{~nm}$. The percentage of nitric oxide scavenging activity was calculated as follows.

$$
\% R S A=\frac{\text { Abs control }- \text { Abs sample }}{\text { Abs control }} \times 100
$$

Where, RSA is the nitric oxide scavenging activity;

Abs control is the absorbance of tube test without extract;

Abs sample is the absorbance of tube test with extract

\section{Results}

- $\quad$ Physical properties

- $\quad$ Physical properties of HaE represented in table 2.

- Appearance and odor: HaE the cream was white-yellowish semisolid cream without odor.

- Consistency and feeling: HaE cream was smooth and cold cream.

- $\quad$ Loss on drying: LOD was $15.4 \%$ at temperature $105^{\circ} \mathrm{C}$.

- $\mathrm{pH}$ : The $\mathrm{pH}$ of the cream was found to be in the range of 7 which is good for skin $\mathrm{pH}$.

- Viscosity, spreadability, and diffusion: The viscosity of cream was $25240 \mathrm{cps}$ which indicates that the cream is easily spreadable by $38 \mathrm{~g} \mathrm{~cm} / \mathrm{sec}$ and easily diffuse by $0.3 \mathrm{~cm}$.

- Phase separation: recorded at medium and high speed.

- Density and Solubility; Density of HaE cream was 0.89 (g/cm3) while the cream was insoluble in alcohol, ether, DMSO, acetone, and soluble in xyole.

- Thermal Stability: cream was thermally stable at 37o,25o, and 2oc. There was no phase separation.

- HaE cream was easy to remove by Extrudability reach to $93 \%$.

\subsection{Irritancy test}

There was no sign of redness and itching and safe for topical application.

Table 2 Physical properties of HaE cream.

\begin{tabular}{|l|l|}
\hline Color & White yellowish \\
\hline Odor & Odorless \\
\hline Appearance & Semisolid \\
\hline Consistency & Smooth \\
\hline Felling & Cold \\
\hline Loss on drying (\%) & 15.4 \\
\hline pH & 7 \\
\hline Spread ability (sec) & 38 gcm/sec \\
\hline Diffusion study (cm) & 0.3 \\
\hline Phase separation & at medium and high speed \\
\hline Viscosity (cps) & 25240 \\
\hline Density (g/cm ${ }^{3}$ ) & 0.89 \\
\hline
\end{tabular}


GSC Biological and Pharmaceutical Sciences, 2020, 13(02), 232-239

\begin{tabular}{|l|l|}
\hline Thermal Stability & Stable \\
\hline Stability & Stable at $37^{\circ}, 25^{\circ}$ and $2^{\circ} \mathrm{C}$ \\
\hline Solubility & $\begin{array}{l}\text { Insoluble in (alcohol, ether, DMSO, aceton) } \\
\text { Soluble in xyole }\end{array}$ \\
\hline Irritancy & Non-irritant \\
\hline Extrudability & $93 \%$ \\
\hline
\end{tabular}

\subsection{Free radical scavenging activity}

The results of DPPH scavenging activity of HaE cream are shown in the figure 1. The radical scavenging activities were estimated by comparing the percentage of inhibition of DPPH radicals by the cream. The present results showed that $\mathrm{HaE}$ cream has in vitro antioxidant activity as indicated by dose dependent inhibition of DPPH radicals in range from 57 to $70 \%$.

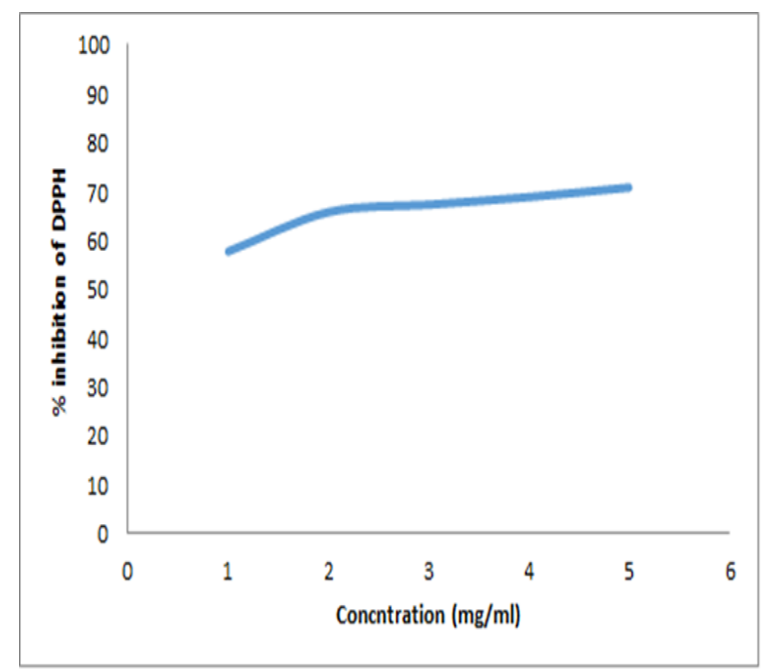

Figure 1 Radical scavenging activity of HaE cream

\subsection{Nitric oxide (NO) scavenging activity}

The results of NO scavenging activity of $\mathrm{HaE}$ cream are shown in the figure 2. The present results showed that HaE cream has in vitro NO scavenging activity in range from 25 to $49 \%$.

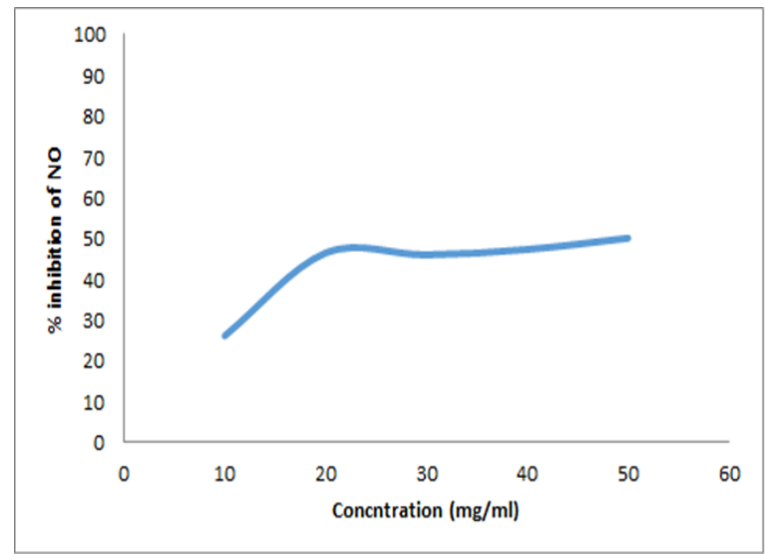

Figure 2 NO scavenging activity of HaE cream 


\section{Discussion}

For the therapeutic strategies of skin-aging and age-related skin diseases, it is important to find an antioxidant compound that is able to be applied to the human body for cleansing, beautifying, promoting attractiveness, or altering the appearance without affecting body structure or functions. During the course of evolution, many invertebrates have been established as a selective advantage by endogenous production of protective chemicals. Sea cucumbers are rich in several bioactive compounds, including saponin, chondroitin sulfate, collagen, amino acids, and phenols. These bioactive compounds have diverse functional roles as a secondary metabolite and these properties can be applied to the developments of novel cosmeceuticals. Therefore, the present study developed a topical skincare cream (w/o) loaded with the sea cucumber, Holothuria arenicola (HaE) extract.

Oxidative stress has been suggested to play a role in ultraviolet (UV) damage mediated melanogenesis and reduction on skin elasticity [22]. The application of active antioxidant substances in cosmetic formulations stems from their ability to protect the skin against oxidative damage by UV radiation and aging. Most skincare formulations claiming anti-aging effects are based on exogenous antioxidants such as vitamins, polyphenols, and flavonoids that cannot be synthesized by our body. A direct idea about the antioxidant competence of a compound can be obtained by 1,1-diphenyl-2picrylhydrazyl (DPPH) assays. DPPH is a synthetic-free radical which can be effectively scavenged by antioxidants [23]. It has been widely used for rapid evaluation of the antioxidant activity of cream formulations [24]. In the present study, the ability of formulated HaE cream to scavenging DPPH radicals was determined by the decrease in its absorbance at $517 \mathrm{~nm}$. The overproduction and metabolites of nitric oxide (NO) have been implicated in the development of pathologies although it is extremely important to defend the body [25]. Therefore, NO production blocking agents might be beneficial for the treatment of the inflammatory response. The antioxidant activity of the formulated HaE cream may be due to its high content of antioxidant phenolic compound, chlorogenic acid. Phenolic compounds represent one of the most important antioxidants which play an important role as free radical scavengers, reducing agents, and quenchers.

The $\mathrm{pH}$ is a significant parameter as far as the effectiveness of the cream is concerned. The skin is naturally acidic in nature as it typically ranges from 4.5 to 6.0 [26] and this acidity plays an important role in the skin's defense mechanisms and overall skin health. The present study showed that formulated H. arenicola cream was found homogenous, easily washable, and had neutral $\mathrm{pH}$ which was compatible with normal skin physiology.

Spreadability consists in the expansion of a semi-solid formulation on a surface after a certain time, and its determination is important because topical products should be easy to apply on the skin surface [27]. The results obtained showed that the prepared cream having a good appearance, smooth texture, and easily spreadable property. The low value of the spreadability coefficient of the cream was sufficient suggesting easy spreading. The lower value of spreadability indicates the lesser work required to spread the cream over the skin, which means the formulation was easily spreadable by applying a small amount of shear. Viscosity is a useful process indicator of emulsion quality, as it is highly sensitive to changes in the emulsion due to variations in process and formulation parameters. The viscosity of formulated $\mathrm{HaE}$ cream was found at $25240 \mathrm{cps}$ which indicates that the cream is easily spreadable by small amounts of shear. It has been reported that increase the viscosity of emulsion formulations is an important approach that is used to ensure a more controlled application of products, and the production of a uniform, thick, and effective sunscreen film on the skin [28]. In addition, no phase separation was observed for the formulated HaE cream stored at different conditions for 28 days. This indicated stable formulation, considering phase separation as a parameter of stability. Depending on the conditions, the cream may be more stable at a lower temperature due to increased phase viscosity.

In conclusion, the formulated $\mathrm{HaE}$ cream was successfully developed that met the relevant pharmaceutical characteristics form. The developed HaE cream could be added in topical formulations in order to protect skin against damage caused by free radicals due to its antioxidant activity. The developed HaE cream is a potential candidate for conducting further clinical studies.

\subsubsection{The Conflict of Interest}

- Ayman Saber Mohamed disclose that there are no conflict of interest

- Sohair Ramadan Fahmy disclose that there are no conflict of interest

- Abdelaziz A. A. Elsayed disclose that there are no conflict of interest 


\section{Compliance with ethical standards}

\section{Acknowledgments}

The authors extend their appreciation to to the Faculty of Science, Cairo University, Egypt for supporting the current work.

\section{Disclosure of conflict of interest}

The Conflict of Interest

All authors disclose that they have no conflict of interest

\section{References}

[1] Sharma HD, Paramesh R. Trends in aging and skin care: Ayurvedic concepts. Journal of Ayurveda and Integrative Medicine. 2010; 1: 110-113.

[2] Nguyen VP, Kim SW, Kim H, Kim H, Seok KH, Jung MJ, et al. Biocompatible astaxanthin as a novel marine-oriented agent for dual chemo-photothermal therapy. PLoS One. 2017; 12(4): e0174687.

[3] Ruiz-Ruiz F, Mancera-Andrade EL, Iqbal HM. Marine-Derived Bioactive Peptides for Biomedical Sectors: A Review. Protein Pept Lett. 2017; 24(2): 109-117.

[4] Packer JF, Da Luz MM, Para Avaliação E, Pesquisa D. Antimicrobiana De Produtos De Origem Natural. Revbrasfarmacogn. 2007; 17(1): 102-107.

[5] Saraf S, Kaur C. hytoconstituents as photoprotective novel cosmetic formulations. Pharmacogn. Rev. 2010; 4: 111.

[6] Imhoff JF, Labes A, Wiese J. Bio-mining the microbial treasures of the ocean:New natura lproducts. Biotechnol. Adv. 2011; 29: 468-482.

[7] Siahaan EA, Pangestuti R, Hendra Munandar H, Kim S. Cosmeceuticals Properties of Sea Cucumbers:Prospects and Trends. Cosmetics. 2017; 4: 26.

[8] Gil ML, Tomás-Barberán FA, Hess-Pierce B, Holcroft DM, Kader AA. Antioxidant activity of pomegranate juice and its relationship with phenolic composition and processing. J Agric Food Chem. 2000; 48: 4581-4589.

[9] Oresajo C, Stephens T, Hino HD, Law RM, Yatskaye M, Foltis P, et al. Protective effects of a topical antioxidant mixture containing vitamin C, ferulic acid, and phloretin against ultraviolet-induced photodamage in human skin. J Cosmet Dermatol. 2008; 4(7): 290-7.

[10] Oresajo C, Pillai S, Manco M, Yatskayer M, McDaniel D. Antioxidants and the skin: understanding formulation and efficacy. Dermatol Ther. 2012; 25(3): 252-9.

[11] Magalhães J. 0 uso de cosméticosatravés dos tempos, envelhecimentocutâneo. In: Rubio, Ed.,Com questões de avaliação. Rio de Janeiro. 2000; 33-42.

[12] Salavkar SM, Tamanekar RA, Athawale RB. Antioxidants in skin ageing - Future of dermatology. Int J Green Pharm. 2011; 5: 161-168.

[13] Yasumoto T, Nakamura K, Hashimoto Y. A new saponinholothurin isolated from the sea cucumber Holothuriavagabunda. Agricultural Biolology and Chemistry. 1967; 31: 7.

[14] Rajasree RH, Vishwanad V, Cherian M, Eldhose J, Singh R. Formulation and evaluation of antiseptic polyherbal ointment. Int. J.Of Pharm. \& Life Sci. 2012; 3(10): 2021-2031.

[15] Chakole CM, Shende MA, Khadatkar SN. Formulation and evaluation of novel combined halobetasolpropionate and fusidic acid ointment. International Journal of Chem Tech Research. 2009; 1: 103-116.

[16] Kavitha AN, Deepthi V, Naira N. Design, Formulation And Evaluation Of A Polyherbal Ointment For Its WoundHealing Activity. Pharmacophore. 2013; 4(5): 175-180.

[17] Prasad A, Kumar MD, Prabhudutt P. Formulation and evaluation of cream prepared from croton sparsiflorusMorong and their wound healing activity. IJRAP. 2012; (3): 803-807. 
[18] Akanksha D, Vikas G, Neetesh KJ, Shailendra S, Neelam B, Dinesh KJ. Formulation and Evaluation of Neomycin Sulphate Ointment containing Natural Wound Healing Agent Curcuma longa. International Journal of Pharmaceutical Sciences and Drug Research. 2009; 1(2): 116-118.

[19] Keshwar A, Keshwar U, Deogirkar A, Dhurde SS, Deo V, Shrikhande BK. FORMULATION DEVELOPMENT AND EVALUATION OF CREAM CONTAINING NATURAL ESSENTIAL OILS HAVING MOSQUITO REPELLENT PROPERTY. WORLD JOURNAL OF PHARMACY AND PHARMACEUTICAL SCIENCES. 2016; 5(8): 1586-1593.

[20] Sanchez-Moreno C, Larrauri JA, Saura-Calixto F. Aprocedure to measure the antiradical efficiency of polyphenols. J. Sci. Food Agric. 1998; 76: 270-276.

[21] Govindarajan R, Rastogi S, Vijayakumar M, Shirwaikar A, Rawat AK, Mehrotra S, et al. Studies on antioxidant activities of Desmodium gangeticum. Biol Pharm Bull. 2003; 26(10): 1424-7.

[22] Panich U, Onkoksoong T, Limsaengurai S, Akarasereenont P, Wongkajornsilp A. UVA-induced melanogenesis and modulation of glutathione redox system in different melanoma cell lines: The protective effect of gallic acid. J. Photochem Photobiol. 2012; 108: 16-22.

[23] Villano D, Fernandez-Pachona MS, Moyab ML, Troncosoa AM, Garcia-Parrilla MC. Radical scavenging ability of polyphenolic compounds towards DPPH free radical. Talanta. 2007; 230: e235.

[24] Damle M, Mallya R. Development and Evaluation of a Novel Delivery System Containing Phytophospholipid Complex for Skin Aging. AAPS PharmSciTech. 2016; 17(3): 607-17.

[25] Wadsworth TL, Koop DR. Effects of Ginkgo biloba extract (EGb 761) and quercetin on lipopolysaccharide-induced release of nitric oxide. Chem-Biol. Interact. 2001; 137: 43-58.

[26] Jennifer LM, Karen LC, Ibulaimu K, Philip FS, David JS. valuation of the effect of pH on in vitro growth of Malassezia pachydermatis. Can. J. Vet. Res. 2003; 67: 56-59.

[27] BORGHETTI GS, KNORST MT. Desenvolvimento e avaliação da estabilidade física de loções O/A contendo filtros solares. Braz. J. Pharm. Sci. 2006; 42(4): 531-537.

[28] Cross SE, Jiang R, Benson HA, Roberts MS. Can increasing the viscosity of formulations be used to reduce the human skin penetration of the sunscreen oxybenzone? J Invest Dermatol. 2001; 117(1): 147-50. 